\title{
Does dietary calcium have a protective effect on bone fractures in women? A meta-analysis of observational studies
}

\author{
Liangzhi $\mathrm{Xu}^{*}$, Patrick McElduff ${ }^{\dagger}$, Catherine D’Este and John Attia \\ Centre for Clinical Epidemiology and Biostatistics (CCEB), School of Population Health Sciences, Faculty Health, \\ The University of Newcastle, Australia
}

(Received 6 June 2003 - Revised 24 November 2003 - Accepted 6 December 2003)

\begin{abstract}
It is generally accepted that supplemental Ca and/or vitamin D is effective in reducing the incidence of bone fractures; this is supported by numerous randomised controlled trials and meta-analyses. However, a question that has received much less attention is whether dietary Ca, i.e. $\mathrm{Ca}$ in physiological doses in normal food intake, also affects bone fracture risk. The present study aims to review the effect of dietary $\mathrm{Ca}$ on bone fractures at the hip, spine and radius in women $>35$ years old, and to compare these results with previous meta-analyses. MEDLINE (1966-1999) and reference lists in papers were searched for observational dietary Ca studies. Data were extracted in duplicate and separately. Heterogeneity and publication bias were tested. Observational studies failed to show any association between dietary Ca intake and risk of hip fracture (risk ratio 1.01, $95 \%$ CI 0.96, 1.07 for each increment of $300 \mathrm{mg}$ dietary Ca intake/d). There is a suggestion that either extremely low $\mathrm{Ca}$ intake may increase fracture risk, or that East Asian women may respond differently to increasing Ca intake.
\end{abstract}

Calcium: Fractures: Meta-analysis

Because of the mortality and morbidity associated with bone fractures, it is more important and more cost-effective to prevent rather than to treat fractures in elderly women (Riggs \& Melton, 1988; Chrischilles et al. 1994). It is generally accepted that supplemental $\mathrm{Ca}$ and/or vitamin $\mathrm{D}$ is effective in reducing fracture risk; this is supported by numerous randomised controlled trials and meta-analyses using both clinical fractures and bone mineral density as outcomes (Cumming, 1990; Cumming \& Nevitt, 1997; Gillespie et al. 2000). However, a question that has received much less attention is whether dietary $\mathrm{Ca}$, i.e. $\mathrm{Ca}$ in physiological doses in normal food intake, also affects bone fracture risk. Whereas randomised controlled trials answer the question: 'Does supplemental $\mathrm{Ca}$ and/or vitamin D reduce fracture risk?', observational studies answer the question: 'Is $\mathrm{Ca}$ at normal dietary doses linked to fracture risk?'. The implication would be that low dietary $\mathrm{Ca}$ might be a risk factor for fractures, or alternatively, that $\mathrm{Ca}$ at the highest doses seen in normal diets, i.e. short of supplementation, might be protective.

The only previous meta-analysis of observational studies showed that every increment of $300 \mathrm{mg}$ in dietary Ca intake/ $\mathrm{d}$ was associated with an odds ratio of hip fracture of 0.96 (95\% CI 0.93, 0.99) (Cumming \& Nevitt, 1997). This result is qualified by several caveats. Some of the observational study results used in the pooled analysis were based on very low follow-up rates, subjective diagnosis of fracture or a single source of dietary $\mathrm{Ca}$ intake. Likewise, the pooled results of observational studies were based on a fixed effects model, even though there was heterogeneity ( $P$ value for heterogeneity 0.02). These caveats shed doubts on the conclusions.

To clarify the effect of dietary $\mathrm{Ca}$ intake on bone fractures, the present review was undertaken. Our aim was to review observational studies (including cohort and casecontrol studies) to determine if low dietary $\mathrm{Ca}$ intake is one of the risk factors for forearm, vertebral and hip fractures in women aged $>35$ years after adjusting for the effect of age.

\section{Materials and methods}

Selection of studies for review

The inclusion criteria for studies were defined as follows:

(1) Observational studies published in English;

(2) Outcomes were hip, forearm or vertebral fractures;

(3) Diagnosis of fracture was objective: e.g. diagnosed by X-ray or other objective test such as computerised tomography, or reported in medical records;

(4) Quantitative dietary $\mathrm{Ca}$ intake was derived from at least three types of foods that were rich in $\mathrm{Ca}$;

(5) More than thirty study subjects at entry;

(6) Subjects aged $>35$ years, and results adjusted for age;

\footnotetext{
* Corresponding author: Dr Liangzhi Xu, present address: Department of Obstetrics and Gynaecology, The Second West China Hospital, Sichuan University, Chengdu, China, fax + 86288555 9065, email liangzxu@mail.sc.cninfo.net

$\dagger$ Present address: The Medical School, The University of Manchester, Oxford Road, Manchester M13 9PT, UK
} 
(7) Studies only in women or, if both male and female subjects were included in a study, data could be extracted for women separately, or adjusted for gender, or conditional logistic regression analysis was used for matched sets;

(8) Follow-up rate for cohort studies or response rate for case-control studies $>50 \%$;

(9) Length of follow-up at least 1 year for cohort studies.

\section{Information retrieval}

Information retrieval was done by two of the investigators (L. X. and J. A.) with the help of two librarians specialising in database searches. MEDLINE was used to search for studies reported in English from 31 December 1999 using the following search terms: combination of 'fracture*' and ' $\mathrm{Ca}$ '; limited to female and human studies.

In addition, studies were identified from the reference lists of obtained papers, editorials and known studies. Authors were contacted if not enough data were included in the paper for analysis. The title and abstract of studies identified in the computerised search were scanned by two of the investigators (L. X. and J. A.) separately to exclude any that clearly did not meet the inclusion criteria. If the abstract and title did not provide sufficient grounds for acceptance or rejection, the original papers were retrieved. Differences were resolved by consensus. The full texts of the papers were retrieved for data extraction.

\section{Data extraction and methodological quality assessment}

For each included study, data extraction was performed by L. X. and J. A. separately. Differences were resolved by consensus.

The 'osteoporosis meta-analysis quality assessment form' for cohort and case-control studies derived by Robertson (1995) was modified to assess the methodological quality of the primary observational articles (see Tables 1 and 2 for details of rating scales).

\section{Statistical analyses}

Quality scores were used to provide information and explore reasons for heterogeneity, but not to weight studies. The intraclass correlation coefficient was used to examine the level of agreement for the quality scores between the two coders. This was calculated using a twoway ANOVA (Morton \& Dobson, 1989) and using the total quality scores of each paper.

Heterogeneity of effect was tested for all studies using a general variance-based method (Sharp \& Stern, 1997; Bradburn et al. 1998). If the $P$ value was $<0 \cdot 2$, pooling was rejected and reasons for the heterogeneity were examined by regressing the mean effect against each of the following factors individually: age, ethnicity, study design, method of $\mathrm{Ca}$ measurement, mean dietary $\mathrm{Ca}$ intake level, year of data collection, response rate and/or follow-up rate, follow-up period, continent (Europe or North America) where the study was performed, quality score. These factors were defined a priori. Both unweighted and weighted methods (weighting by reciprocals of the variance) were used to check the results.

To check for publication bias, funnel plots were drawn and assessed using Egger's test (Egger et al. 1997).

Meta-analysis was performed using the method of Greenland \& Longnecker (1992). Estimates of the linear association between dosage of $\mathrm{Ca}$ and the natural $\log$ of the odds ratio for hip fracture for each study were calculated. The dosage of $\mathrm{Ca}$ intake in each study was calculated as the midpoint of each $\mathrm{Ca}$ intake category. For the openended upper category of $\mathrm{Ca}$ intake, the median intake was estimated as the lower bound plus $30 \%$. The weighted mean values of the individual slopes were pooled to provide the summary risk ratio based on a fixed effects model.

The meta-analysis was done using STATA (version 6.0; Stata Corporation, College Station, TX, USA) and the method of Greenland \& Longnecker (1992) was implemented in SAS (version 6.12; Statistical Analysis Systems Inc., Cary, NC, USA).

\section{Results}

The intraclass correlation coefficient for scoring agreement between two reviewers was 0.98 . The results at different sites studied will be described separately later.

We identified 1582 publications on MEDLINE. Titles and abstracts were scanned to exclude those clearly irrelevant, such as studies addressing bone turnover, pure hormone therapy or cost-effectiveness analysis. The full texts of the remaining papers ( $n$ 47) were viewed; fourteen of these observational studies met the inclusion criteria. Two of the fouteen studies (Cummings et al. 1995; Schulz et al. 1995) were excluded due to duplicate reports. This left twelve studies covering: North America (USA, Canada), Europe (Italy, UK, Sweden, Norway) and East Asia (China). Four were prospective cohort studies and eight were case-control studies. Among eligible studies, one (Cumming et al. 1997) investigated hip, forearm and vertebral fractures (data could be extracted separately), one investigated hip and forearm fractures (Kreiger et al. 1992; data could be extracted separately), one investigated vertebral fractures (Chan et al. 1996) and the remainder investigated hip fractures. Because of the limited number of studies addressing vertebral and forearm fractures, only results of studies analysing the relationship between dietary $\mathrm{Ca}$ intake and hip fractures were pooled.

\section{Calcium intake and forearm fractures}

The two observational studies regarding $\mathrm{Ca}$ intake and forearm fractures (Krieger et al. 1992; Cumming et al. 1997) arrived at different conclusions: the cohort study by Cumming et al. (1997) did not show a protective effect of dietary $\mathrm{Ca}$ intake on forearm fractures, while a case-control study (Krieger et al. 1992) showed an odds ratio of 0.18 (95\% CI $0.04,0.81)$ when $\mathrm{Ca}$ intake was $>1000 \mathrm{mg} / \mathrm{d}$ compared with $\mathrm{Ca}$ intake $<800 \mathrm{mg} / \mathrm{d}$. Both of these studies took into account $\mathrm{Ca}$ supplements in separate analyses. 
Table 1. Methodological quality assessment criteria for cohort study

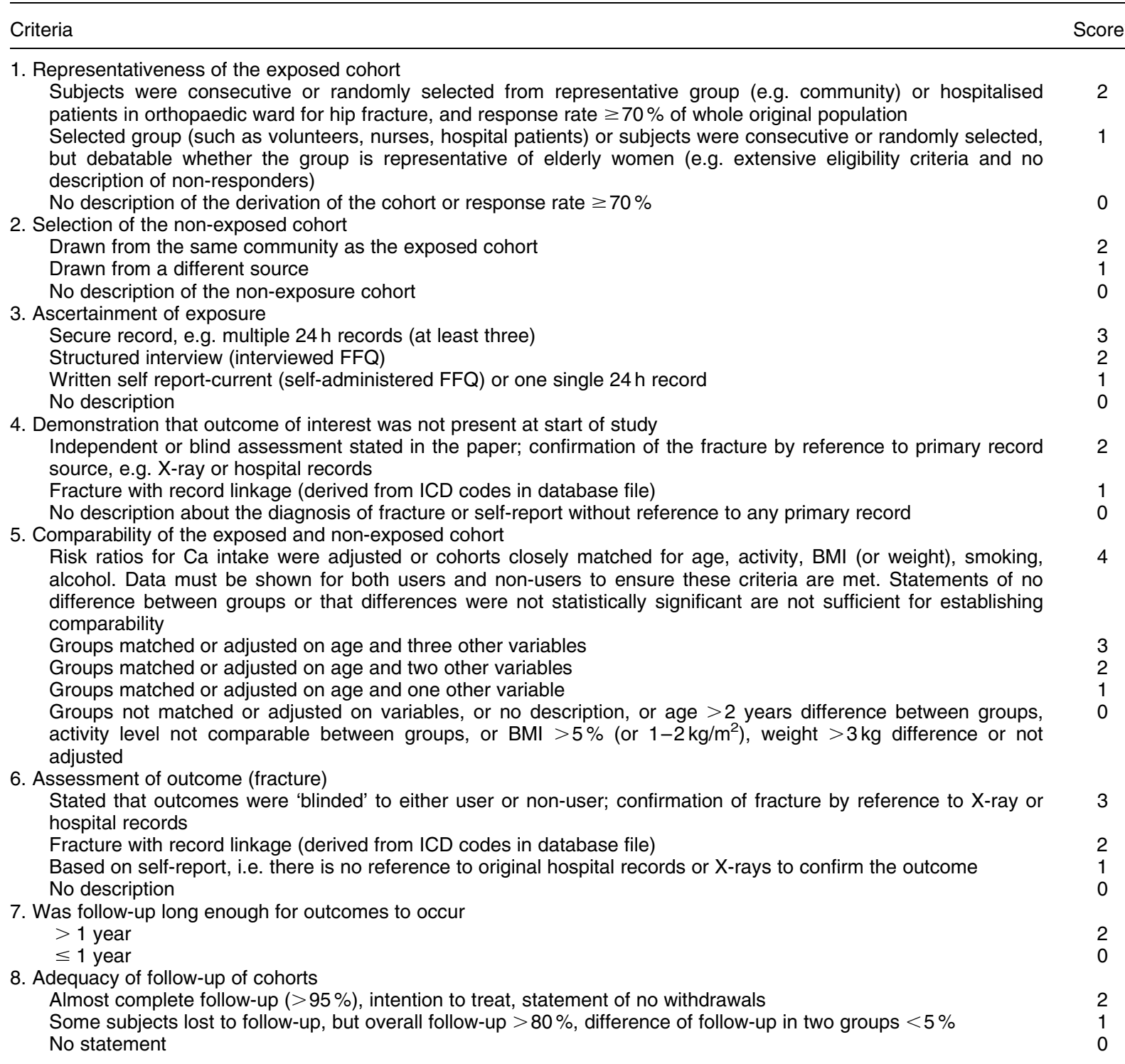

FFQ, food-frequency questionnaire; ICD, International Classification of Diseases.

* Total score 20

\section{Calcium intake and vertebral fractures}

Two studies addressed vertebral fractures (Chan et al. 1996; Cumming et al. 1997). In a case-control study, Chan et al. (1996) found that those with a dietary Ca intake $<247 \mathrm{mg} / \mathrm{d}$ had an odds radio of vertebral fracture of $2.1(95 \%$ CI $1.1,3.9)$ compared with those whose $\mathrm{Ca}$ intake was $>382 \mathrm{mg} / \mathrm{d}$. In a cohort study Cumming et al. (1997) did not find any protective effect with a high Ca intake. Only Cumming et al. (1997) took Ca supplements into account in separate analyses.

\section{Relationships between dietary calcium intake and hip fractures}

Summaries of the characteristics and results of the eleven observational studies addressing hip fractures are shown in Tables 3 and 4 (Cooper et al. 1988; Lau et al. 1988; Wickham et al. 1989; Paganini et al. 1991; Krieger et al. 1992; Nieves et al. 1992; Looker et al. 1993; Michaelsson et al. 1995; Tavani et al. 1995; Cumming et al. 1997; Meyer et al. 1997). Four were prospective studies, two were nested case-control studies and five were case-control studies.

The mean follow-up period in cohort studies ranged from 5.2 to 14.6 years. The loss to follow-up ranged from 1 to $41 \%$. Response rates in case-control studies ranged from 61 to $97 \%$ in cases and 56 to $97 \%$ in controls. The methods used for dietary $\mathrm{Ca}$ intake were foodfrequency questionnaire (nine studies), $7 \mathrm{~d}$ record (one study) and $24 \mathrm{~h}$ recall (one study). The quality score for case-control studies ranged from 9 to 13 out of a possible 18 with average of 11 (SD 1.5); for cohort studies it ranged from 11 to 17 out of 20, with an average of 14 (SD 2.6). 
Table 2. Methodological quality assessment criteria for case-control study

Criteria $\quad$ Score*

1. Is case definition adequate?

Fracture with independent validation, ie. Reference to primary record source, e.g. X-ray or hospital record

Fracture with record linkage (derived from ICD codes in database file) or self-report without reference to any primary record

No description about the diagnosis of fracture

2. Representativeness of the cases

Consecutive or randomly selected from representative group (e.g. community) or hospitalised patients in orthopaedic ward for hip fracture, and response rate $\leq 70 \%$ of whole original population

Selected group (such as volunteers, nurses, hospital patients) or cases were consecutive or randomly selected but debatable whether the group is representative of elder women (e.g. extensive eligibility criteria and no description of non-responders)

No method of selection described or response rate $<70 \%$

3. Selection of controls

Controls were consecutive or randomly selected from the same community as the fractured group (have the same eligibility criteria unless no fracture) and response rate $\geq 70 \%$ of whole original population

Control group was matched at onset with fracture group for baseline characteristics, or subjects drawn from a different source to the fracture group but low degree of mismatch or selected group (such as volunteers, nurses, hospital controls)

No mention of selection described or controls drawn from a different source to the fractured group and high degree of mismatch, or response rate $<70 \%$

4. Definition of controls

If cases are first fracture, then must explicitly state that controls have no history of hip, forearm or vertebral fracture. If cases were new hip, forearm and vertebral fracture (not necessarily first fracture), then controls should not exclude those with previous hip, forearm and vertebral fracture

No description of history of fracture in controls or have different fracture history from cases (e.g. cases were first fracture, while controls had previous history of fracture, or cases were new fracture while controls excluded those with previous fracture)

5. Comparability of cases and controls

Odds ratios for $\mathrm{Ca}$ intake were adjusted or groups closely matched for age ( \pm 2 years), activity, and weight $\left( \pm 3 \mathrm{~kg}\right.$ ) (or BMl $\pm<5 \%$ or $\pm 1-2 \mathrm{~kg} / \mathrm{m}^{2}$ ), smoking, alcohol. Results must be shown for both cases and controls to ensure these criteria are met. Statements of no difference between groups or that differences were not statistically significant or not sufficient for establishing comparability.

Groups matched or adjusted on age and three other variables

Groups matched or adjusted on age and two other variables

Groups matched or adjusted on age and one other variable

Groups not matched or adjusted on variables, or no description, or age $>2$ years difference between groups, activity level not comparable or weight $>3 \mathrm{~kg}$, or BMI $>5 \%\left(\right.$ or $\left.1-2 \mathrm{~kg} / \mathrm{m}^{2}\right)$ difference or not adjusted.

6. Ascertainment of exposure

Objective measure, e.g. multiple $24 \mathrm{~h}$ prospective records (at least three) or weighted food intake (at least $4 \mathrm{~d}$ )

Structured interview (interviewed FFQ) where blind to case or control status

Interview not blinded to case or control status

Written self-report or medical record only (self-administered FFQ or one single $24 \mathrm{~h}$ food record)

No description

7. Same method of ascertainment of previous Ca intake in cases and controls? Or blinded assessment of calcium intake Yes

No

8. Non-response rate

Same rate for both groups or difference between groups $\leq 5 \%$

Non-respondents described, or response rate difference between groups $5-10 \%$

Rate difference between groups $>10 \%$ or no information

There was evidence of heterogeneity across the eleven studies $(Q 21.342, P=0.019)$ addressing the association of hip fracture with dietary $\mathrm{Ca}$ intake. Regression analysis of the mean effect $v$. each of the following factors: age, ethnicity, study design, method of $\mathrm{Ca}$ measurement, mean dietary $\mathrm{Ca}$ intake level, year of data collection, response rate and/or follow-up rate, follow-up time (years), continent (Europe or North America) where the study was performed and quality score, showed that only ethnicity (Western or East Asian) had a clear relationship with mean effect; this was because of one study in Chinese women in Hong Kong who had very low $\mathrm{Ca}$ intake (median value 128 (interquartile range $75-176$ ) $\mathrm{mg} / \mathrm{d}$;
Lau et al. 1988) and high soyabean intake, with phyto-oestrogens providing protection from bone loss in ageing noted in East Asian populations (Potter et al. 1998; Messina, 1999). After removing this study, the pooled estimate among studies of white subjects showed no heterogeneity ( $Q 11.402, P=0.249)$. The funnel plot showed no evidence of publication bias (Egger's test $t 0.540, P=0.604$; see Fig. 1). It was not possible to show that dietary $\mathrm{Ca}$ was associated with hip fractures (risk ratio 1.01, 95\% CI 0.96, 1.07) (Fig. 2).

When the three study designs (prospective, nested case-control and case-control) were analysed separately, the pooled estimate of each study design showed no 


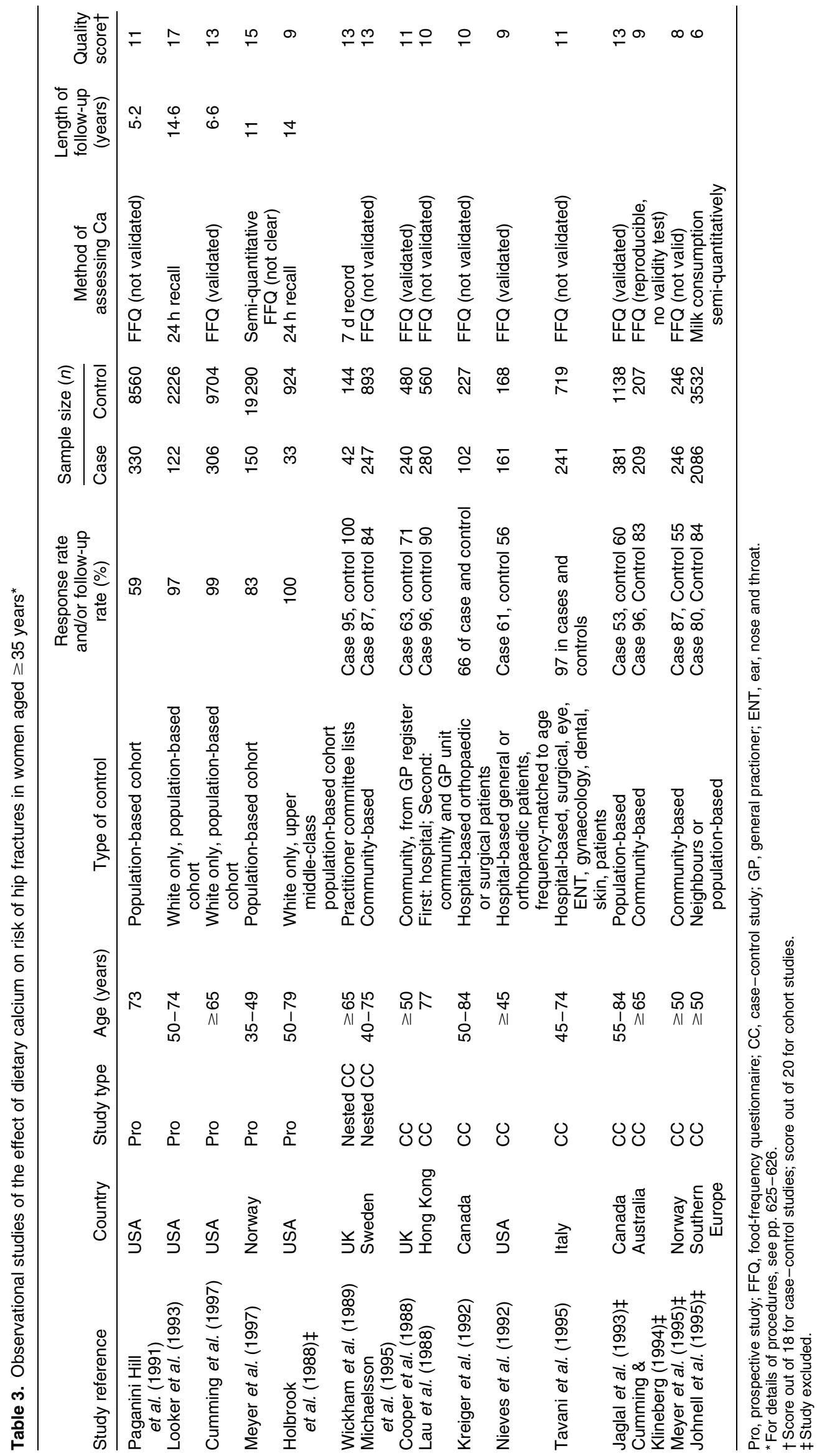




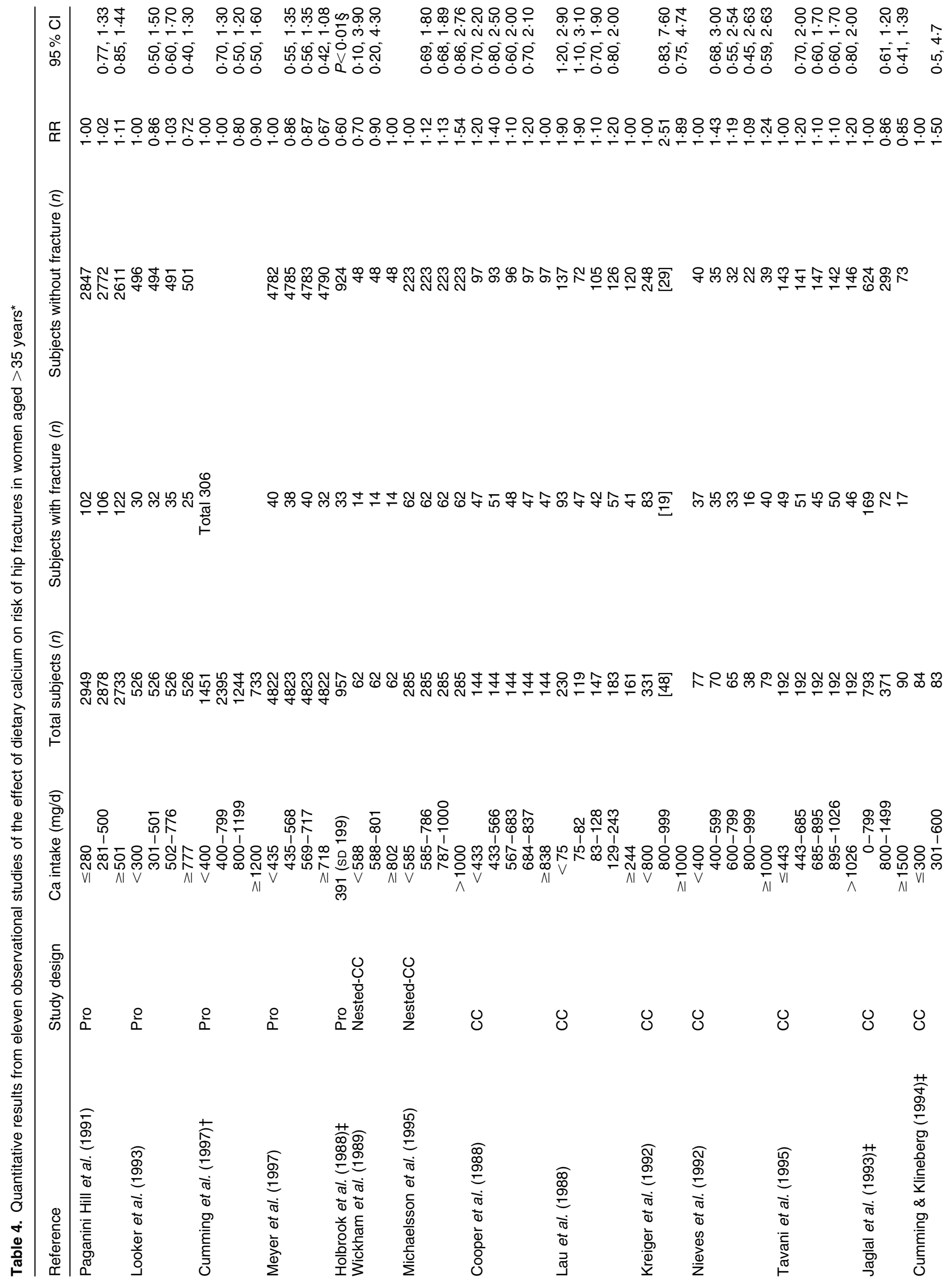




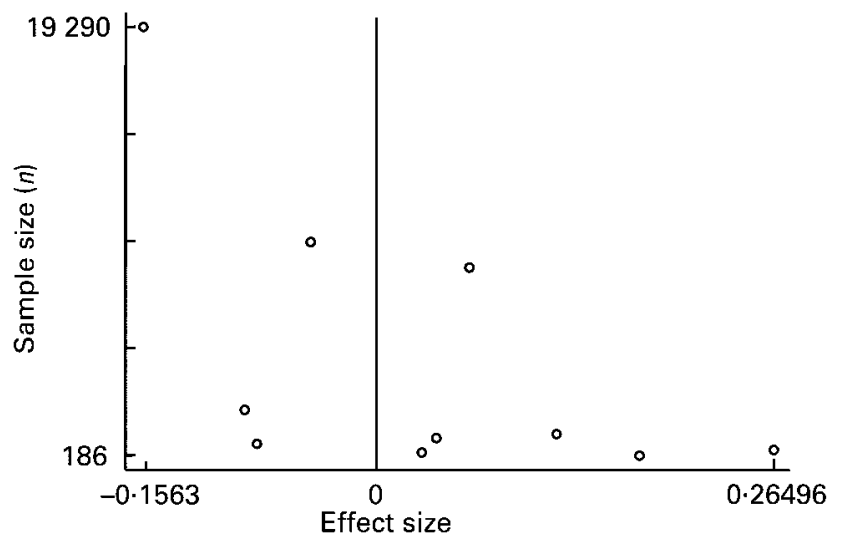

Fig. 1. Funnel plot for ten observational studies of the effect of dietary calcium on hip fracture in women aged $\geq 35$ years. For details of procedures, see pp. 625-626. The effect size was the slope of the line relating calcium quartile to hip fractures.

heterogeneity. In addition, the separate pooled risk ratios did not show any association between dietary $\mathrm{Ca}$ and hip fractures for each of the three study designs (Table 5).

The study conducted in East Asia (Lau et al. 1988) was the only one to show a very strong protective effect of increased $\mathrm{Ca}$ intake on hip fractures; the odds ratio was $0.48(95 \%$ CI $0.30,0.76)$.

\section{Discussion}

The present review of observational studies failed to show that dietary $\mathrm{Ca}$ intake was related to risk of hip fracture in adult white women aged $>35$ years, except when $\mathrm{Ca}$ intakes were very low. This is different from the metaanalysis of Cumming \& Nevitt (1997). There are multiple reasons for this discrepancy, as follows.

Some studies were not included even though they had been included previously in the other meta-analyses, because the present study used relatively strict inclusion and exclusion criteria. Five observational studies included in meta-analysis of Cumming \& Nevitt (1997) were excluded. One was excluded because of lack of objective diagnosis of fracture (Holbrook et al. 1988), one due to very low follow-up rate (36.1\%; Jaglal et al. 1993), two due to lack of quantitative data (we contacted the authors, but received no reply; Cumming \& Klineberg, 1994; Meyer et al. 1995) and one due to the fact that Ca intake was derived only from milk (Johnell et al. 1995). Among these studies, two showed Ca (Holbrook et al. 1988) or milk (Johnell et al. 1995) consumption had a protective effect; the other three did not show this effect. The two studies that showed protective effects had relatively large sample sizes (2086 cases and 3532 controls in the study of Johnell et al. (1995) and 957 in the cohort of Holbrook et al. (1988), while the other three studies had 837 cases and 1591 controls in total). Sensitivity analysis, including the results by Cumming \& Klineberg (1994), did not change the results.

We did not pool the results when there was significant heterogeneity, while the other meta-analyses pooled results using the fixed-effects model despite heterogeneity ( $P$ for heterogeneity 0.02; Cumming \& Nevitt, 1997). 


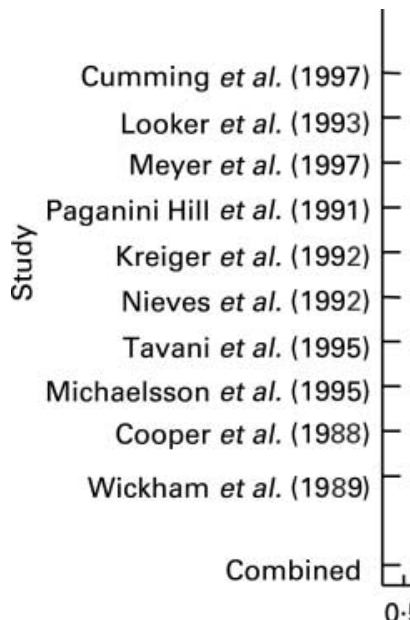

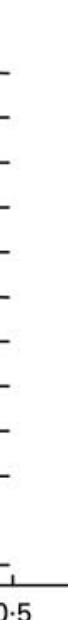

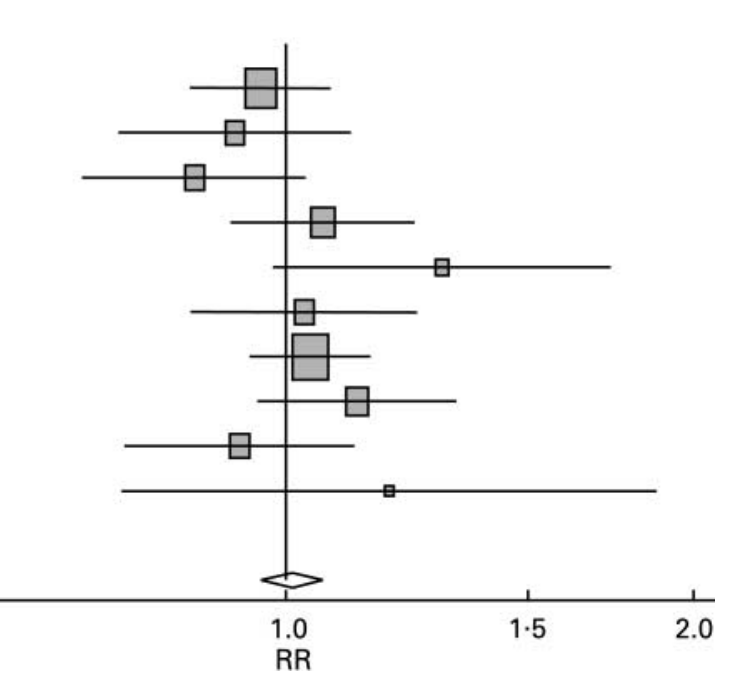

Fig. 2. Pooled risk ratio (RR) and $95 \%$ confidence intervals for dietary calcium on hip fracture in ten observational studies in women aged $\geq 35$ years (excluding study in Hong Kong). For details of procedures, see pp. 625-626.

In the present study, we excluded studies if Ca intake was estimated from less than three sources; this was done to ensure that $\mathrm{Ca}$ intakes were not underestimated, since subjects derive $\mathrm{Ca}$ from multiple sources. The three major sources of $\mathrm{Ca}$ intake in western countries are whole milk, cheese and skimmed milk, which account for about $40 \%$ Ca intake (Block et al. 1985; Krogh et al. 1993; Favero et al. 1997). Studies using one source of Ca intake account for about one-fifth and using two sources about one-third of $\mathrm{Ca}$ intake at most, even when the most $\mathrm{Ca}$-rich foods such as milk and/or cheese were included (Block et al. 1985; Krogh et al. 1993; Favero et al. 1997); using these methods would severely underestimate $\mathrm{Ca}$.

One of the reasons that dietary Ca intake was not related to risk of hip fracture in adult white women aged $>35$ years might be that the baseline dietary $\mathrm{Ca}$ intakes in the included studies were relatively high: from $>300 \mathrm{mg} / \mathrm{d}$ (Holbrook et al. 1988: cases 320, controls $401 \mathrm{mg} / \mathrm{d}$ ) or median value $371 \mathrm{mg} / \mathrm{d}$ (Paganini Hill et al. 1991) to median value 730 (interquartile range $537-882$ ) $\mathrm{mg} / \mathrm{d}$ (Wickham et al. 1989). The relatively higher level of baseline dietary $\mathrm{Ca}$ intake might be enough to maintain blood levels, basic physiological functions and bone health. Thus, the increases in $\mathrm{Ca}$ intake offer no more protective effect for fractures. When the baseline intake of $\mathrm{Ca}$ is very low, as in the Hong Kong study (Ca intake: cases 128 (range 75-176), controls 168 (range 76-214) mg/d; Lau et al. 1988), the increased $\mathrm{Ca}$ intake may only maintain blood levels and basic physiological functions, but not be sufficient to strengthen bones and provide a protective effect for fractures. When the $\mathrm{Ca}$ intake increases further, increased intake not only maintains blood $\mathrm{Ca}$ levels, but can also be deposited in bone tissues to strengthen bone and prevent fractures. However, it is not clear if the protective effect of $\mathrm{Ca}$ intake has an upper limit beyond which the bone needs for $\mathrm{Ca}$ are saturated; this needs exploration.

There are many reasons why East Asian women differ from white women in this regard. They might include not only dietary habits such as low dietary $\mathrm{Ca}$ intake, low milk intake, high soyabean intake (Lau et al. 1988; Fujita \& Fukase, 1992) and accompanying low protein intake (Nordin, 2000), but also other lifestyle factors such as types and levels of activity (Fujita \& Fukase, 1992; Anderson, 2000), bone structure (Fujita \& Fukase, 1992) and vitamin D receptor polymorphisms (Young et al. 1996). Further studies of specific East Asian populations are warranted to test the hypotheses.

\section{Limitations of the present study}

In any meta-analysis certain methodological points must be addressed.

(1) The present analysis only included studies published in English and retrieved on MEDLINE. Thus 'grey literature' (e.g. unpublished studies and company reports) or

Table 5. Separate estimates for each study design using fixed models*

\begin{tabular}{lccccccc}
\hline & \multicolumn{7}{c}{ Heterogeneity } \\
\cline { 3 - 4 } Study design & No. of studies & $Q$ & $P$ & Pooled RR & $95 \% \mathrm{Cl}$ \\
\hline All studies & 10 & 11.402 & 0.249 & 1.01 & 0.96 & 1.07 \\
Prospective & 4 & 3.287 & 0.349 & 0.96 & 0.89 & 1.04 \\
Nested case-control & 2 & 0.049 & 0.824 & 1.14 & 0.97 & 1.33 \\
Case-control & 4 & 3.776 & 0.287 & 1.04 & 0.96 & 1.12 \\
\hline
\end{tabular}

$\mathrm{RR}$, risk ratio.

*For details of procedures, see pp. 625-626. 
abstracts were not included. Exclusion of this literature has been shown to increase the estimate of the intervention effect by 10-15\% (Egger et al. 2002), and exclusion of abstracts to further increase the effect size by about $30 \%$ (McAuley et al. 2000). However, there are problems with the practice of including grey literature: poor study quality due to lack of peer review (Angell, 1989), incomplete inclusion, and limitation of time, effort and cost involved in identifying, locating and retrieving grey literature (McAuley et al. 2000). Abstracts may not escape publication bias, since they also need to be peer reviewed before acceptance and presentation; positive abstracts are also easier to publish than negative abstracts (McAuley et al. 2000).

(2) Additional results also indicate that restricting searches to MEDLINE misses many controlled trials, which will overestimate effects by about $5 \%$ (Egger et al. 2002), although the quality of studies identified through searching by hand or using other databases, e.g. EMBASE, does not differ from those on MEDLINE (Suarez-Almazor et al. 2000) and would not be expected to bias the summary effect size.

(3) The present meta-analysis was restricted to studies pubished in the English language. Some researchers have found that language restriction may affect results (Gregroire et al. 1995), causing a $10 \%$ overestimation (Egger et al. 2002); other work has not borne this out (Moher et al. 2000).

All these factors would lead to an overestimate in the pooled effect and may be detected by the tests for publication bias. Since the Egger test was not significant and the pooled estimate showed no effect, we believe that these are not active issues in our present study.

Even though relatively strict inclusion and exclusion criteria were established, the quality of included studies was still not satisfactory. Most of the instruments of $\mathrm{Ca}$ intake measurement were not validated. The representativeness of some studies was not clear. The duration of $\mathrm{Ca}$ intake measured was not clear for some studies. The difference of response rate in cases and controls were large in some studies. The review of subjects was unblinded in some studies. The recall bias between cases and controls was not mentioned in some studies. All of these issues might bias the combined results towards increasing the effect of dietary $\mathrm{Ca}$ on bone fractures, as seen in the previous meta-analyses.

\section{Conclusions}

Our conclusions are as follows.

(1) The data are very sparse and it is hard to draw any firm conclusion. However, the fact that several studies showed major differences in relationships (albeit not significant within study) does make one pessimistic that an effect is present. Our interpretation is that as long as $\mathrm{Ca}$ intake is within a reasonable range, there is no effect on hip fractures. Increasing dietary $\mathrm{Ca}$, short of supplementation, is probably not an effective preventative measure for hip fractures in white women aged $>35$ years.

(2) At very low $\mathrm{Ca}$ intakes, the risk of fractures may increase. The only significant effect of dietary $\mathrm{Ca}$ on hip fractures was seen in the one study that included patients with very low dietary $\mathrm{Ca}$ intake. Because this study was also carried out in East Asian subjects, it is unclear whether it is the very low dietary $\mathrm{Ca}$ intake, soyabean intake in East Asian people or ethnicity that led to this effect. If further studies in East Asian countries confirm this, it would mean that East Asian subjects might be more sensitive to Ca compared with white subjects and lead to the identification of genetic factors in bone response to $\mathrm{Ca}$.

(3) There are insufficient data to make any conclusions about the effect of dietary $\mathrm{Ca}$ on spine and forearm fractures.

A need exists for additional well-designed studies explicitly exploring the effects of increasing lengths of followup, age group and ethnicity on dietary $\mathrm{Ca}$ in postmenopausal women. The data suggested that $\mathrm{Ca}$ intake might have greater effects in East Asian populations than white. However, the evidence from East Asian countries was from a very small number of studies (only one from Hong Kong). More studies (both observational and experimental) from East Asian countries are needed to address this issue.

The discrepancies between our present results and previous meta-analyses also send a cautionary note about the potential bias introduced into meta-analytical results by the inclusion of lower quality trials and failure to address heterogeneity.

\section{Acknowledgements}

The authors would like to thank Associate Professor Richard Prince, Dr John Buxton, Dr Nick Pocock, Stephen Mears, Tony Siarkiewicz, Miss Annette Moxey, Ms Jane Robertson and Ms Ann Wilkinson for their help in offering additional information, quality scoring system revision, information retrieval and data extraction.

\section{References}

Anderson JJ (2000) The important role of physical activity in skeletal development: how exercise may counter low calcium intake. Am J Clin Nutr 71, 1384-1386.

Angell M (1989) Negative studies. New Engl J Med 321, 464-466.

Block G, Dresser CM, Hartman AM \& Carroll MD (1985) Nutrient sources in the American diet: quantitative data from the NHANES II survey. I. Vitamins and minerals. Am J Epidemiol 122, 13-26.

Bradburn MJ, Deeks JJ \& Altman DG (1998) Metan - an alternative meta-analysis command. Stata Tech Bull 44, 4-15.

Chan HH, Lau EM, Woo J, Lin F, Sham A \& Leung PC (1996) Dietary calcium intake, physical activity and the risk of vertebral fracture in Chinese. Osteoporos Int 6, 228-232.

Chrischilles E, Shireman T \& Wallace R (1994) Costs and health effects of osteoporotic fractures. Bone 15, 377-386.

Cooper C, Barker DJ \& Wickham C (1988) Physical activity, muscle strength, and calcium intake in fracture of the proximal femur in Britain. Br Med J 297, 1443-1446.

Cumming RG (1990) Calcium intake and bone mass: a quantitative review of the evidence. Calcif Tissue Int 47, 194-201.

Cumming RG, Cummings SR, Nevitt MC, Scott J, Ensrud KE, Vogt TM \& Fox K (1997) Calcium intake and fracture risk: 
results from the study of osteoporotic fractures. Am J Epidemiol 145, 926-934.

Cumming RG \& Klineberg RJ (1994) Case-control study of risk factors for hip fractures in the elderly. Am J Epidemiol 139, $493-503$.

Cumming RG \& Nevitt MC (1997) Calcium for prevention of osteoporotic fractures in postmenopausal women. $J$ Bone Miner Res 12, 1321-1329.

Cummings SR, Nevitt MC, Browner WS, Stone K, Fox KM, Ensrud KE, Cauley J, Black D \& Vogt TM (1995) Risk factors for hip fracture in white women. New Engl J Med 332, 767-773.

Egger M, Davey Smith G, Schneider M \& Minder C (1997) Bias in meta-analysis detected by a simple, graphical test. $\mathrm{Br}$ Med $\mathrm{J}$ 315, 629-634.

Egger M, Ebrahim S \& Smith GD (2002) Where now for metaanalysis? Int J Epidemiol 31, 1-5.

Favero A, Salvini S, Russo A, Parpinel M, Negri E, Decarli A, La Vecchia C, Giacosa A \& Franceschi S (1997) Sources of macro- and micronutrients in Italian women: results from a food frequency questionnaire for cancer studies. Eur $J$ Cancer Prev 6, 277-287.

Fujita T \& Fukase M (1992) Comparison of osteoporosis and calcium intake between Japan and the United States. Proc Soc Exp Biol Med 200, 149-152.

Gillespie W, Avenell A, Henry D, O'Connell D \& Robertson J (2000) Vitamin D and vitamin D analogues for preventing fractures associated with involutional and post-menopausal osteoporosis (Cochrane Review). Oxford, UK: Update Software Ltd.

Greenland S \& Longnecker MP (1992) Methods for trend estimation from summarized dose-response data, with applications to meta-analysis. Am J Epidemiol 135, 1301-1309.

Gregoire G, Derderian F \& Le Lorier J (1995) Selecting the language of the publications included in a meta-analysis: is there a Tower of Babel bias? J Clin Epidemiol 48, 159-163.

Holbrook TL, Barrett Connor E \& Wingard DL (1988) Dietary calcium and risk of hip fracture: 14-year prospective population study. Lancet 2, 1046-1049.

Jaglal SB, Kreiger N \& Darlington G (1993) Past and recent physical activity and risk of hip fracture. Am J Epidemiol 138, 107-118.

Johnell O, Gullberg B, Kanis JA, et al. (1995) Risk factors for hip fracture in European women: the MEDOS Study (Mediterranean Osteoporosis Study). J Bone Miner Res 10, 1802-1815.

Kreiger N, Gross A \& Hunter G (1992) Dietary factors and fracture in postmenopausal women: a case-control study. Int $J$ Epidemiol 21, 953-958.

Krogh V, Freudenheim JL, D’Amicis A, Scaccini C, Sette S, Ferro-Luzzi A \& Trevisan M (1993) Food sources of nutrients of the diet of elderly Italians: II. Micronutrients. Int J Epidemiol 22, 869-877.

Lau E, Donnan S, Barker DJ \& Cooper C (1988) Physical activity and calcium intake in fracture of the proximal femur in Hong Kong. Br Med J 297, 1441-1443.

Looker AC, Harris TB, Madans JH \& Sempos CT (1993) Dietary calcium and hip fracture risk: the NHANES I Epidemiologic Follow-Up Study. Osteoporos Int 3, 177-184.

McAuley L, Pham B, Tugwell P \& Moher D (2000) Does the inclusion of grey literature influence estimates of intervention effectiveness reported in meta-analyses? Lancet 356, $1228-1231$

Messina M (1999) Legumes and soybeans: overview of their nutritional profiles and health effects. Am J Clin Nutr 70, Suppl. 3, 439S-450S.

Meyer HE, Henriksen C, Falch JA, Pedersen JI \& Tverdal A (1995) Risk factors for hip fracture in a high incidence area: a case-control study from Oslo, Norway. Osteoporos Int 5, 239-246.

Meyer HE, Pedersen JI, Loken EB \& Tverdal A (1997) Dietary factors and the incidence of hip fracture in middle-aged Norwegians. A prospective study. Am J Epidemiol 145, 117-123.

Michaelsson K, Holmberg L, Mallmin H, Sorensen S, Wolk A, Bergstrom R \& Ljunghall S (1995) Diet and hip fracture risk: a case-control study. Int J Epidemiol 24, 771-782.

Moher D, Pham B, Klassen T, Schulz KF, Berlin JA, Jadad AR \& Liverati A (2000) What contributions do languages other than English make on the results of meta-analyses? J Clin Epidmiol 53, 964-972.

Morton AP \& Dobson AJ (1989) Assessing agreement. Med J Aust 150, 384-387.

Nieves JW, Grisso JA \& Kelsey JL (1992) A case-control study of hip fracture: evaluation of selected dietary variables and teenage physical activity. Osteoporos Int 2, 122-127.

Nordin BEC (2000) Calcium requirement is a sliding scale. Am J Clin Nutr 71, 1381-1383.

Paganini Hill A, Chao A, Ross RK \& Henderson BE (1991) Exercise and other factors in the prevention of hip fracture: the Leisure World study. Epidemiology 2, 16-25.

Potter S, Baum J, Teng H, Stillman R, Shay N \& Erdman JJ (1998) Soy protein and isoflavones: their effects on blood lipids and bone density in postmenopausal women. Am J Clin Nutr 68, Suppl., 1375S-1379S.

Riggs BL \& Melton LJD (1988) Osteoporosis and age-related fracture syndromes. Ciba Found Symp 134, 129-142.

Robertson J (1995) Study quality: Development and testing of instruments for evaluation of interventions in postmenopausal osteoporosis, pp. 153-154. M Med Sci Thesis, University of Newcastle, Australia.

Schulz KF, Chalmers I, Hayes RJ \& Altman DG (1995) Empirical evidence of bias. Dimensions of methodological quality associated with estimates of treatment effects in controlled trials. J Am Med Assoc 273, 408-412.

Sharp S \& Sterne J (1997) Meta-analysis. Stata Tech Bull 38, $9-14$.

Suarez-Almazor ME, Belseck E, Homik J, Dorgan M \& RamosRemus C (2000) Identifying clinical trials in the medical literature with electronic databases: MEDLINE alone is not enough. Control Clin Trials 21, 476-487.

Tavani A, Negri E \& La Vecchia C (1995) Calcium, dairy products, and the risk of hip fracture in women in northern Italy. Epidemiology 6, 554-557.

Wickham CA, Walsh K, Cooper C, Barker DJ, Margetts BM, Morris J \& Bruce SA (1989) Dietary calcium, physical activity, and risk of hip fracture: a prospective study. $\mathrm{Br}$ Med $\mathrm{J} \mathbf{2 9 9}$, 889-892.

Young RP, Lau EM, Birjandi Z, Critchley J \& Woo J (1996) Interethnic differences in hip fracture rate and the vitamin D receptor polymorphism. Lancet 348, 688-689. 